\title{
1 Distinctive issues in the history of medicine in antiquity
}

\author{
Geoffrey E. R. Lloyd
}

The comparative history of premodern medicine is, arguably, the most challenging of all areas of historical study. It shares some general problems, those of translation and interpretation for instance, with other fields. But it adds several further layers of difficulties. Let me give first an elucidation and elaboration of these two points.

First of all, as in the investigation of such matters as the understanding of physical changes, we are often faced with theorists and practitioners who make use of some pretty obscure and ambiguous concepts. What did different Greek authors mean by such key terms as chumos ('humour' - but was that a pathogen, or the result or sign of disease, or again a natural ingredient in the body?) or phlebes (are these veins or arteries or any type of vessel?) or pepsis ('concoction': how is this supposed to work? What models are in mind?) or krisis (the turning point at which a condition is exacerbated or alternatively is resolved) or kairos (the moment of opportunity which may also be a 'crisis' in our sense) or melancholia (a classic case where at different times and in different authors we find what appear to be physical factors mixed in with psychological ones)? Where the Graeco-Roman legacy is involved, there is a further complication in the adaptations and reinterpretations, not to say distortions, that occur in later European usages: think of what happens to the term husteria when it gets to be a psychological diagnosis! ${ }^{1}$

Analogously, ancient Chinese medicine presents us with such problems as the interpretation of terms like $q i$ (those who do not just transliterate brave it out with talk of breath/energy, though quite how those two are meant to combine is pretty problematic, is it not?) or mai or mo (what kind of structure or process, vessel or pulse, are these?) or feng ('wind', though that can be internal to the body) or shanghan (this word can be translated as 'cold damage', but what counts as such?).

Problem number one is how the ancient authors on whom we depend as our sources understood the conceptual framework they use (and how any particular use resembles or differs from others who employed the very same terms, either at the very same period or at different times). How did they understand whatever pathological conditions with which they were confronted? In other words, how did they conceptualise disease, and did they acknowledge any of the distinctions that some modern commentators have used, namely between subjective illness 
and objective disease, between not feeling well and suffering from some pathological complaint? Usually most problematic of all, how were mental health and its antonyms, all the way from some mental disturbance to 'madness', conceived?

The next complicating factor arises when we try to come to terms with the treatments that were favoured. Take the herbal and mineral remedies to which our texts refer, where it is well known how tricky their identification can be. The translations offered in the standard Greek lexicon, Liddell-Scott-Jones, are often seriously misleading, especially where plants are concerned, as my mentor John Raven revealed in a damning critique (Raven 2000). The problem was that Liddell-Scott-Jones relied heavily on the advice they received from ThiseltonDyer, Director of Kew Gardens, and he was altogether too zealous in proposing Linnaean binomials for ancient Greek plant names. In both the ancient GraecoRoman world and in China (cf. Métailié 2015), the same plant could be called by different names in different places and times; conversely, the same name might refer to different plants.

Then, when we come to the effects described or claimed for the treatments in question, we again often find ourselves floundering. What did such accounts owe to the imaginations of the doctors or their patients? How do we make due allowance for the placebo effect? It is all very well to attempt retrospective diagnoses and interpretations on the basis of modern biomedical knowledge, but usually the descriptions in our texts are too indeterminate to allow these to be secure. What is represented as a single disease may well have been extremely complex. I believe that to be the case even with many accounts of what was labelled 'the plague', although there have been some successes in narrowing down the possibilities of the pathogens involved. If the patients are described as recovering, was that due to the treatment they received or simply to the vis curatrix naturae? Again, when the patients died, was that in part the result of their treatment? In some Greek texts, especially, the writers not only describe a high incidence of mortality among their patients but sometimes acknowledge that their own treatments were to blame (Lloyd 1987: chapter 3). In classical Greece, medical malpractice as such was not actionable, so the doctor was only liable if a charge of criminality (rather than just of negligence) could be made, though the situation was to change in Hellenistic and Roman medicine (Amundsen 1977 for classical Greece and 1973 for Rome).

Faced with such a combination of multi-layered indeterminacies, we have to say that the history of premodern medicine is not for the faint-hearted. At the same time, we should not conclude that we are dealing with nothing but the pure fictions of those who wanted to claim they knew what they were doing but really had no basis for that claim. This is where the peculiar challenge of our subject arises. We can use two types of approach or groups of resources to make some headway. There is an interesting tension between these two, but I shall argue we need to combine both to make proper progress.

Let me call the two the 'objective/scientific/positivist', on the one hand, and the 'subjective/sociological', on the other. The first seeks to make the most of what we can learn from modern scientific knowledge, not just in such areas as botany and pharmaceutics, ${ }^{2}$ but also in anatomy, physiology and pathology. Obviously, 
we cannot assume that human beings have remained totally unchanged over the millennia of our existence. Average height, body weight and life expectancy have all undoubtedly increased (not that they are uniform across all human populations today). But archaeological evidence shows that gross anatomical structures have not altered much. We can still easily identify a femur or a metatarsal in skeletons whose radio-carbon dating places them in the Stone Age. Where pathologies are concerned, there are certainly important variations in lactose tolerance and in sickle-cell anaemia which have significant demographic implications. But we can be reasonably confident in at least some of our epidemiologies.

All of this is useful information that can be brought to bear on aspects of our general understanding of the endemic and epidemic diseases of the ancient world. But when we try to identify cases of malaria, or tuberculosis, or bubonic plague, or influenza, or epilepsy, we encounter difficulties of varying degrees of severity. Nowadays we know what causes malaria: but identifying it in ancient texts or in archaeological remains can be tricky. Where the written sources are concerned, we immediately enter the realm of the subjective, where we have to make the most of what we can ascertain about other factors, most notably using our second line of approach, taking into account the interactions of doctors and patients and the assumptions that either of them were making about disease, its causes and its cures.

In most ancient (as in many modern) societies, it is commonly assumed that there is more to suffering a pathological condition than a mere result of some physical interaction taking place in the body. Why a particular patient is afflicted by whatever that condition may be is always liable to be a question that will be pushed further back. Even when a condition has an obvious external cause - the twisted ankle or injured limb is the result of a slip or some heavy object falling on the limb - the question of why the person slipped or why that object fell where and when it did can always be posed as the 'why me?' question that EvansPritchard popularised. Nor is the answer 'he was not being careful enough' or 'the rains had loosened the rock' going to be the end of the matter, since further questions keep cropping up as to why he was distracted or why he happened to be passing when the rock fell.

One feature of accounts of disease, sickness and illness is the recursive character of causal chains. It is true that sometimes causal factors can be traced back to a single major determining item. But far more often, possible complexities have to be taken into consideration. Disease is a classic area where the phenomenon of over-determination occurs. The unfortunate outcome - the crops failing, for example - was not just the result of a mistake on the part of the farmer, but also because of some external agency, for instance a god or some ancestor who had not been properly appeased. How could that further factor ever be ruled out? Hardened sceptics may resist any idea of supernatural intervention on general grounds: but it is only if there is some prior conviction of its impossibility that exceptions will be excluded.

So, this takes us further into what we may call the sociological dimension of health practice, the varying interactions between doctors and patients and their 
differing interpretations of whatever common assumptions they bring to bear, usually from what they have been brought up to believe. Doctors or healers of any kind have a special responsibility: they are supposed to know better than their patients what caused the complaint and what will alleviate if not cure it. The doctor will usually be able to draw on a wide variety of resources, from plant and mineral drugs and possible surgical interventions, all the way to the reassuring effects of a good bedside manner (as it used to be called), let alone prayers, spells, charms and incantations.

The doctor will insist more or less emphatically on his or her expertise, which is hopefully robust enough to inhibit their patients from quibbling about the advice they are given. But patients generally have their own lay views as to why they are sick and what will help (as also to whether the doctor is any good). Patients too can and do appeal to what they maintain are tried and tested methods that they will say have worked in the past, which may or may not tally with those that the selfproclaimed healer is offering. So, there is generally room for negotiation, much more so in premodern situations where the authority of the doctor does not depend on a legally recognised qualification which can only be obtained after years of rigorous training in established institutions.

But these very discussions that we may imagine often occurred between doctor and patient do not usually figure in the records to which the historian has access. When the texts describe individual cases or group epidemics, they generally do so very much from the point of view of the doctor, although to be sure there are some notable instances where lay people themselves report on medical conditions. Thucydides' account of the 'plague' at Athens, which he said he suffered from himself, would be one example. ${ }^{3}$ Obviously when the doctor controls the record, he or she will have a particular agenda - not always a matter of confirming their own authority, but often with just that motive.

But how, we have to ask, does medical authority get to be built up in the first place in premodern situations where there were no legally recognised qualifications, and where indeed biomedical knowledge was in short supply? Up to this point, I have been referring to 'the doctor' in relation to his/her patients. But it is essential to recognise the plurality of medical practitioners for which we have evidence from both China and Greece, as well as from Egypt, Mesopotamia and India. ${ }^{4}$ A crucial part of our investigation of ancient medical practice must, then, be to examine how different types of persons who laid claims to heal the sick developed their specific personae and justified their ideas and practices.

Let me take a little time to survey just how varied those different types were in ancient Greece, although much of this material is by now very familiar. We tend to start with what we know of the medicine practised by the authors of the Hippocratic treatises, the corpus of work collected under his name in Alexandria, though in no case can he be securely identified as the author. Actually, there is good reason to believe that many are multi-authored works compiled over extended periods. But given the different theories of disease and ideas about treatment that we find in those writings, we have to recognise that what we refer to as 'Hippocratic medicine' is not only highly complex but often also largely a construct of whoever 
is writing about it. Rather different accounts are generated depending on which treatises are singled out for particular attention.

It is clear from references to iatroi ('doctors') by non-medical writers, including Plato and Aristotle, that they recognised a group of literate doctors who formed a medical elite; both refer to Hippocrates himself as a particularly famous doctor. In any given case, much no doubt depended on whom any particular doctor could claim to be his teacher; there were certainly city-states that had a reputation for training doctors, even though we should be wary of thinking that all of those who were associated with Cos or with Cnidus or with Croton shared exactly the same views. They clearly did not. But it is more important to recognise that in the very same period that most of the authors represented in the Hippocratic collection were active (that is, in the fifth and early fourth centuries BCE), the cults of Asclepios and other healing gods and heroes, so far from declining in the face of naturalistic medicine, were becoming increasingly popular. Most of the surviving shrines date from the fourth century or later, but it is clear from the outset that socalled temple medicine attracted a clientele from all walks of life. Among those who sponsored the cult when it was first set up in Athens was no less than the tragedian Sophocles. We should accordingly certainly not imagine that those who patronised the healing shrines were drawn solely or even predominantly from the lower echelons of society, from the less well off or the less well educated. Indeed, there is every reason to believe that treatment at the shrines could be quite expensive. Inscriptions refer to those who were unwilling to pay up being punished by the god, although there was generally a happy ending, with the god producing a cure once the fees had been paid.

The range of medical alternatives on offer extends further. We hear of 'rootcutters' and 'drug-sellers' who collected and sold herbal remedies, and did so quite openly in the market-place. ${ }^{5}$ Women healers tended to get labelled maiai, which is often glossed 'midwives', though it is clear that they were called in to deal with far more than childbirth. Some texts indicate indeed that the first recourse of women when they were sick was to other women, though we also have plenty of evidence of male heads of households deciding to call on a 'Hippocratic' doctor. The individual patients listed in the Epidemics include a fair number of women, though to be sure they are outnumbered by males (Lloyd 1983: 67). In the Economica (7 37), Xenophon suggests that the housewife's duties included making sure that the sick in the household were cared for.

So, the range of possible modes of treatment was considerable, and why recourse would be had to one rather than to another depended on a variety of factors which are, for us, usually now just a matter of guesswork. We can, however, be confident in identifying the flaws in two lines of argument that used to be common in an earlier positivist historiography. The first would have it that ancient patients would only appeal to divine or supernatural factors in situations when ordinary remedies were clearly useless. ${ }^{6}$ The second would argue that with the rise of naturalistic Hippocratic medicine, the hold of any such appeal would decline. As to the second, I have already noted that the rise of the cult of Asclepios grew at the very same time as Hippocratic literate medicine did. Indeed, that cult continued to flourish 
throughout Graeco-Roman antiquity and was arguably from its inception the most popular medical tradition. Thus, in the second century CE, the orator Aelius Aristides, a contemporary of Galen, gives us clear testimony to the attractions that the cult had for members of the social elite. The prestige of the pagan shrines only began to decline when Christianity became the official religion, and that led not to an end of healing shrines so much as to their take-over by Christian saints and Christ the Healer Himself. ${ }^{7}$

As to the first positivist assumption, this takes us to a fundamental point. It is clear from the inscriptions at Epidaurus and elsewhere that those who came to the shrines were far from limited to patients whom the Hippocratics would have considered hopeless cases. On the contrary, the god was consulted on mundane problems, not just common illnesses but also in the hope that some item that had been lost or mislaid would be found. But, more importantly, we must recognise that what religious healing offered was not just some physical alleviation (if you were lucky) but also psychological comfort.

Many of us who read the Hippocratic On the Sacred Disease tend to accept the author's verdict that the sellers of charms and incantations were charlatans, tricking their gullible patients into believing that their remedies would do some good, and that they indeed knew which divine or demonic entity was responsible for which variety of the 'sacred disease'. Yet when that author offers his own alternative account of the disease and claims it can be cured, we have to acknowledge that while the description of an epileptic fit is accurate enough, the assertion of its curability was very largely wishful thinking. We can certainly distinguish his naturalistic mode of discourse about cause and cure from that of those who invoked supernatural agencies. But whatever success he achieved depended largely on the expectations of his patients - as indeed we may say was also the case for those who cultivated religious healing. In both cases, we may say that almost everything depended on the prior assumptions of those seeking treatment.

So, the contest between these different modes of medical discourse and practice was much more of a level playing field than positivist historiography would suppose. The Hippocratic author could claim to provide some reassurance that the Sacred Disease was not sent by some god or demon to punish the persons afflicted for the wrong-doing that they or indeed their ancestors had committed. The purifiers and practitioners of temple medicine would for their part offer psychological support if they could convince their patients that the god was on their side, provided they showed their faith in him, supplicated him correctly and paid the dues that were asked for. But in both types of case, the main effect was a matter of psychology.

It is particularly remarkable that we find the vocabulary of 'purification', katharsis, used right across the spectrum of medical practices, even though what was meant by that term differed fundamentally. The naturalist doctors 'purified' the body by purging it, with emetics, suppositories and blood-letting or more mildly just by adjusting diet. The temple doctors 'purified' their patients spiritually, not physically, and we find occasional evidence that they criticised their rivals for their too drastic remedies. The modes of efficacy sought were very 
different. The naturalists hoped that their treatments would indeed alleviate the physical sufferings of their patients. The temple medics' chief weapon was psychological, the assurance that with divine help the sick would recover. Nor is the contrast between the two as clear-cut as I may be thought to have just implied. Some of the naturalists, such as the author of On Regimen, also recommended prayer. ${ }^{8}$ The temple doctors used drugs as well as rituals, even performing imaginary surgical interventions that mimicked those undertaken in some of the Hippocratic treatises.

Where the choice between 'science' and 'magic' or 'superstition' used to be represented as no contest, for 'science' would surely win, we must now be a good deal more cautious. 'Magic' may not work in the sense of producing a physical result. But sometimes the effect aimed at was not a matter of 'efficacy' but rather one of 'felicity' (Tambiah 1968, 1973). Rituals might or might not be believed to have a causal effect, but it was still important that they should be carried out correctly, for that was the right thing to do. We can take an example from what used to be a common practice at Christian weddings in our own society. Does throwing confetti at the bride and groom really ensure their fertility? Many who have no such belief may nevertheless hold that it is the right thing to do. Without the confetti, the wedding would somehow not be a proper one, one carried out according to traditional norms. Maintaining the tradition fostered a sense of group solidarity. Not to complete the ritual correctly would be a disruptive influence, on the group and on the individuals who participated.

This lengthy excursus into some of the complexities of ancient medical practices serves to show the importance of factors that, on the face of it, have nothing to do with the success or failure of medical treatment when judged from a biomedical perspective. Ancient healers of different kinds had to be aware of not just their patients' own expectations but also where they themselves stood in relation to other types of healer. In the medical market-place, they needed to set themselves apart from their rivals. Sometimes, as with 'purification', the tactic was to appropriate a common vocabulary, but then to reinterpret it. Sometimes more aggressive direct attacks were made on rivals, accusing them of ignorance, corruption and fraudulence, though that vocabulary in turn was available for use on either side of any polemic. In any event, we have to revise any assumption that we might make that ancient medicine was just a matter of a simple two-factor relationship, one between doctor and patient, when both were faced with a pathological condition. Rather, the doctors themselves were directly or indirectly involved in explicit or implicit polemic with their competitors, both from within whatever tradition they belonged to, and from other traditions.

We come back to the crucial point about the indeterminacy of what counted as health or well-being. In modern biomedicine, we are obliged to run a battery of tests to measure whether any given patient deviates in any way from what is represented as the norm, adjusted usually for his or her age and sex. None of that was available in any ancient society, even though the signs the patient presented were assessed against some intuitive notion of what is normal. ${ }^{9}$ Yet, while unquantifiable feelings were undoubtedly more important in ancient medical diagnosis than 
they are today, it would be a mistake to suppose that the whole of ancient medical encounters remained within the domain of the subjective. In ancient Greece especially, we have found clear evidence of a recognition not just that the patient may be mistaken, but also that the doctor might be, too. It is particularly remarkable that one group of persons, professional athletes, whom popular opinion hugely admired for their physical strength, were thought by some of the doctors to be potentially especially vulnerable. ${ }^{10}$

Assessing our ancient sources calls for a careful balance between the two contrasting approaches I identified. First there is the question of arriving at a biomedical assessment of the accuracy of ancient understandings, of the causes of diseases, the nature of human physiology and so on - where we would do well to remind ourselves of the limits of our knowledge. Then there is the more difficult task of evaluating the effects, including the effectiveness, of ancient treatments, where we have to acknowledge that much remains obscure when we are dealing with subjective feelings and non-biomedical practices in general. We have indeed to make due allowance for those aspects of health and disease that are not reducible to the biomedical but depend, for example, on the complex social relations of those concerned: the patients, their relatives and their potential healers in all their variety. We may often suspect our ancient writers of extravagant and fanciful claims (though we also noted that there are some notable admissions of mistakes). But if we can get the balance right, we may even learn points that are relevant to health and medical practice today. That at least would be the goal we may set ourselves from our study of the convoluted history of medicine in the ancient world.

\section{Notes}

1 See for example King $(1993,1998)$.

2 Let me give an example from ancient pharmaceutics, from Raven (2000). There are many ancient references to the pain-killing properties of the plant called mandragoras, but modern analysis does not confirm this, at least where 'mandragora' is concerned. However, mandragoras was often prescribed in combination with another plant, huoskuamos ('hyoscyamine') which may indeed have had such properties. The recurrent difficulty with so-called polypharmacy is to determine which of the ingredients is responsible for which effects, and indeed whether the effect results from their combination. See Randolph (1904-05); Staub (1962); Jackson and Berry (1973).

3 Thucydides (2 47-54 and 3 87) [Note: ancient authors are cited according to the standard editions cited in the Oxford Classical Dictionary (Hornblower et al. 2012)]. In Lloyd (2003: chapter 5), I discuss the similarities and differences between Thucydides' account and those we find in the Hippocratic Epidemics, and the motives Thucydides may have had for including his detailed description. He writes his account for it to be useful when (as he assumes to be likely) the plague recurs. He sees himself in fact not just as the diagnostician of moral and political ills (arising from stasis, faction, especially) but also of natural ones.

4 For the distinction and the overlap between the as $\hat{u}$ and the āšipu in our Mesopotamian sources, for example, see Geller (2010). For Egyptian medicine, see Lang (2013), and for Indian, Zysk (1993).

5 Some of our chief evidence comes from Theophrastus: see Lloyd (1983, Part III chapter 2). 
6 This would be analogous to the argument that Malinowski used when he related 'magical' practices to situations of particular difficulty or danger, when ordinary practical methods of coping with a situation broke down (Malinowski 1925).

7 See Nutton (1988: chapter 10, 2004: chapter 19); Temkin (1991: 113); Lloyd (2003: chapter 9).

8 The Hippocratic Oath invokes Apollo, Asclepios, a personified Health, Panacea and 'all the gods and goddesses' as sanctions against any who would break its provisions. Such a formula is no doubt conventional, but certainly not just vacuous.

9 Thus, what the patients' pulse indicated was often judged according to some such assumptions about what would be normal. Galen implies that to assess a patient's pulse correctly, it is important to have had prior experience of that before the patient became ill (On Prognosis 12, CMG V 8.1, 128.4ff.).

10 Aphorisms (I 3).

\section{References}

Amundsen, D. W. (1973) 'The Liability of the Physician in Roman Law', in Kaplus, H. (ed.) International Symposium on Society, Medicine and Law, Jerusalem, March 1972. Amsterdam: Elsevier, 17-30.

Amundsen, D. W. (1977) 'The Liability of the Physician in Classical Greek Legal Theory and Practice', Journal of the History of Medicine and Allied Sciences 32, 172-203.

Geller, M. J. (2010) Ancient Babylonian Medicine. Chichester: Wiley-Blackwell.

Hornblower, S., Spawforth, A. and Edinow, E. (eds.) (2012) The Oxford Classical Dictionary. Fourth edition. Oxford: Oxford University Press.

Jackson, B. P. and Berry, M. I. (1973) 'Hydroxytropane Tiglates in the Roots of Mandragora Species', Phytochemistry 12, 1165-6.

King, H. (1993) 'Once Upon a Text: Hysteria from Hippocrates', in Gilman, S. et al. (eds.) Hysteria Beyond Freud. Berkeley: University of California Press, 3-90.

King, H. (1998) Hippocrates' Woman: Reading the Female Body in Ancient Greece. London: Routledge.

Lang, P. (2013) Medicine and Society in Ptolemaic Egypt. Leiden/Boston: Brill.

Lloyd, G. E. R. (1983) Science, Folklore and Ideology: Studies in the Life Sciences in Ancient Greece. Cambridge: Cambridge University Press.

Lloyd, G. E. R. (1987) The Revolutions of Wisdom: Studies in the Claims and Practice of Ancient Greek Science. Berkeley: University of California Press.

Lloyd, G. E. R. (2003) In the Grip of Disease: Studies in the Greek Imagination. Oxford: Oxford University Press.

Malinowski, B. (1925) 'Magic, Science and Religion', in Needham, J. (ed.) Science, Religion and Reality. London: The Sheldon Press, 19-84.

Métailié, G. (2015) Science and Civilisation in China, Vol. 6.4: Traditional Botanical Knowledge: An Ethnobotanical Approach. Cambridge: Cambridge University Press.

Nutton, V. (1988) From Democedes to Harvey. London: Variorum Reprints.

Nutton, V. (2004) Ancient Medicine. London: Routledge.

Randolph, C. B. (1904-05) 'The Mandragora of the Ancients in Folk-Lore and Medicine', Proceedings of the American Academy of Arts and Sciences 40, 485-537.

Raven, J. E. (2000) Plants and Plant Lore in Ancient Greece. Oxford: Leopard's Press (original publication in Annales Musei Goulandris 8(1990), 129-80).

Staub, H. (1962) 'Über die chemischen Bestandteile der Mandragorawurzel 2. Die Alkaloide', Helvetica Chimica Acta 45(7), 2297-305. 


\section{Geoffrey E. R. Lloyd}

Tambiah, S. J. (1968) 'The Magical Power of Words', Man (NS) 3, 175-208.

Tambiah, S. J. (1973) 'Form and Meaning of Magical Acts: A Point of View', in Horton, R. and Finnegan, R. (eds.) Modes of Thought. London: Faber \& Faber, 199-229.

Temkin, O. (1991) Hippocrates in a World of Pagans and Christians. Baltimore: John Hopkins University Press.

Zysk, K. G. (1993) Religious Medicine: History and Evolution of Indian Medicine. London: Transaction Publishers. 